\title{
Avaliação do Desempenho da Soldagem em Liga de Aço 9Cr-5Mo
}

\author{
(Performance Evaluation of Welding in Steel Alloy 9Cr-5Mo)
}

\author{
Nathália Cândido Figueiredo ${ }^{1}$, Natasha Gomes Lopes ${ }^{2}$, Pedro Helton Magalhães ${ }^{1}$, Víctor Moita Pinheiro ${ }^{2}$, Rodrigo Freitas \\ Guimarães ${ }^{2}$, Hamilton Ferreira Gomes de Abreu ${ }^{1}$ \\ ${ }^{1}$ Universidade Federal do Ceará (UFC), Departamento de Engenharia Metalúrgica e de Materiais/Laboratório de Caracterização de \\ Materiais, Fortaleza, Ceará, Brasil.e-mail: nathaliacfigueiredo@gmail.com \\ ${ }^{2}$ Instituto Federal de Educação, Ciência e Tecnologia (IFCE), Curso de Tecnologia em Manutenção Industrial, Maracanaú, Ceará, \\ Brasil.
}

\section{Resumo}

O desenvolvimento de novas ligas de aço requer uma avaliação criteriosa das suas propriedades bem como de seu desempenho frente às condições de operação de acordo com a aplicação a que se destina. Entre estas propriedades pode ser citada a soldabilidade, uma vez que na maioria das vezes estas ligas são empregadas na condição como soldada. O objetivo deste estudo foi analisar o efeito da soldagem MIG em ligas ferríticas contendo 5\% de Mo. Corpos de prova da liga solubilizada foram submetidos à soldagem automática pelo processo MIG. Três niveis de energia com diferentes valores de corrente e velocidade de soldagem foram selecionados, resultando em cinco condições de soldagem. A amostra soldada foi submetida à caracterização das regiões termicamente afetadas e do metal de base através de exames metalográficos, por microscopia ótica, MEV e EDX, para verificar o efeito da energia de soldagem na microestrutura das mesmas. Foram realizados ensaios de dureza Vickers visando levantar um perfil de microdureza da liga. Os resultados indicaram a presença de precipitados identificados como sendo martensita. Com exceção aos precipitados observados, nenhum outro defeito, como a presença de trincas, foi observado nos corpos de prova soldado para os diferentes parâmetros empregados.

Palavras-chave: Soldagem; Molibdênio; Aço Ferrítico.

Abstract: The development of new steel alloys requires a careful evaluation of their properties as well as its performance against the conditions of operation according to the intended application. Among these properties can be cited the weldability, since in most cases, these alloys are used in the welded condition. The aim of this study was to analyze the effect of GMAW in ferritic alloy containing 5\% Mo. Specimens annealed alloy were submitted to automatic GMAW. Three energy levels with different values of current and welding speed were selected, resulting in five welding conditions. The welded samples passed through the characterization of heat-affected regions and the base material through metallographic examination by optical microscopy, SEM and EDX, to determine the effect of welding power in the microstructure. Microhardness tests were performed in order to raise a Vickers hardness profile of the alloy. The results indicated the presence of precipitates identified as martensite. Except for precipitates observed, no other defects, such as the presence of cracks, were observed in specimens welded to the different parameters used.

Key-words: Welding; Molibdenum; Ferritic Steel.

\section{Introdução}

O setor de Petróleo e Gás Natural tem enfrentado diversos problemas associados à extração, transporte e processamento do petróleo. A realidade atual é que as novas jazidas de petróleo apresentam índices de acidez cada vez mais elevados. O processamento de petróleos de alta acidez é economicamente atrativo, o que torna fundamental a procura por novos materiais para fabricar componentes que suportem estes elevados índices de acidez na extração e processamento do petróleo [1].

Aços Cr-Mo têm sido amplamente empregados para esta

(Recebido em 29/02/2012; Texto final em 07/03/2012).

Artigo originalmente publicado no CONSOLDA 2011 aplicação. Estes aços, normalmente contendo entre 1-2\% de Mo e 2,5-11\% de Cr, apresentam boa resistência a altas temperaturas e à corrosão por sulfetos. No entanto, tem-se observado que esses materiais não têm tido um desempenho satisfatório na presença de fluidos com altas velocidades e turbulências. Como alternativa para enfrentar esse problema, uma estratégia que tem sido adotada pelas empresas produtoras de petróleo é o uso de metalurgia especial, através do aumento de Mo nos aços [1,2].

O Mo aumenta a resistência do material a atmosferas ácidas não oxidantes, à corrosão localizada e a resistência a altas temperaturas [3].

$\mathrm{O}$ aumento do teor de molibdênio até $7 \%$ em peso nos aços inoxidáveis austeníticos foi estudado por Wu et al [4]. Eles concluíram que o molibdênio melhora sensivelmente a resistência à corrosão naftênica nestes aços. Esta melhora se deve, entre outros fatores, ao aumento da resistência à corrosão 
por pites devido a melhorias na microestrutura e na dureza [4].

O desenvolvimento de novas ligas de aço requer uma avaliação criteriosa das suas propriedades bem como de seu desempenho frente às condições de operação de acordo com a aplicação a que se destina. Entre estas propriedades pode ser citada a soldabilidade, uma vez que na maioria das vezes estas ligas são empregadas na condição como soldada. Dessa forma, torna-se importante determinar o efeito dos parâmetros de soldagem e, consequentemente, dos diferentes níveis de energia e sua influência na microestrutura dessas ligas.

Entre os parâmetros de soldagem, destacam-se a tensão (U), a corrente (I) e a velocidade de soldagem (Vs). O ajuste inadequado destes parâmetros pode ocasionar defeitos na região da solda, comprometendo ou até mesmo inviabilizando a sua aplicação. Por exemplo, o emprego de valores elevados de corrente pode levar a ocorrência de porosidade e mordeduras, os quais são concentradores de tensões, indesejáveis em juntas soldadas. Já o emprego de baixos níveis de energia de soldagem pode ocasionar falta de penetração, bem como falta de fusão, que é um severo concentrador de tensões. Por último, o ajuste inadequado da velocidade poderá resultar em defeitos de penetração, principalmente pelo emprego de velocidades altas, que também resultará num cordão de aspecto irregular [5].

As ligas $\mathrm{Fe}-\mathrm{Cr}$ são consideradas materiais de baixa soldabilidade, pois sua solda é caracterizada por baixas ductilidade e tenacidade, além da sensibilidade à corrosão intergranular. Trincas de solidificação também podem ocorrer na zona fundida. Estes problemas de soldabilidade têm limitado, até recentemente a aplicabilidade destes aços a estruturas soldadas $[5,6]$.

Outro problema na soldagem de ligas ferríticas é o crescimento de grão. Este crescimento de grão favorece a fragilização e queda na tenacidade das regiões soldadas, responsável pela maior dificuldade na soldagem de aço ferríticos $[7,8]$. O problema de crescimento de grão pode ser minimizado pela aplicação de baixas energias de soldagem que reduzem a velocidade de crescimento e a extensão dos grãos [9].

O molibdênio atua na formação de uma microestrutura ferrítica, assim como o cromo. O aumento no teor de molibdênio, além de proporcionar um aumento da resistência mecânica e elevar a dureza do aço, favorece a formação de precipitados intermetálicos do tipo sigma $(\sigma)$, chi $(\chi)$ e mu $(\mu)$, o que prejudica a soldabilidade dos aços devido à perda de ductilidade. Após tratamento térmico ou soldagem, são necessárias altas taxas de resfriamento para evitar a formação destes precipitados $[2,10]$.

Desta forma o objetivo deste trabalho foi analisar o desempenho da soldagem com adição de material em liga 9Cr5 Mo quando submetida a diferentes níveis de energia através da variação da corrente e da velocidade de soldagem.

\section{Materiais e Métodos}

A composição química da liga estudada (denominada Liga E1) está mostrada na Tabela 1. Esta liga foi fabricada por fundição, laminada a quente, cuja temperatura de início de laminação foi de $1000^{\circ} \mathrm{C}$.
Tabela 1. Composição química da liga estudada.

\begin{tabular}{c|c|c|c|c|c}
\hline Liga & $\mathrm{C}$ & $\mathrm{Mn}$ & $\mathrm{Si}$ & $\mathrm{Cr}$ & $\mathrm{Mo}$ \\
\hline $\mathrm{E} 1$ & 0,030 & 0,37 & 0,34 & 9,5 & 5,3 \\
\hline
\end{tabular}

Utilizando um programa termodinâmico comercial, foi levantado o diagrama de fases com base nos teores de elementos apresentados conforme Tabela 1, identificando as possíveis fases a se formarem.

Inicialmente foi feita a caracterização microestrutural da liga na condição solubilizada, através de microscopia óptica, utilizando o reagente Vilella para revelar a microestrutura [11], seguida pelo levantamento percentual de possíveis fases presentes através da técnica de difração de elétrons retro espalhados (EBSD). Em seguida foram realizados ensaios de microdureza Vickers.

Posteriormente, foi realizada a soldagem com adição de material, empregando o processo MIG automático. A geometria da junta foi definida conforme as normas AWS B2.1:2005 e ASME IX: 2004, em forma de barra chata com espessura de 12 $\mathrm{mm}$, largura $70 \mathrm{~mm}$, comprimento de $250 \mathrm{~mm}$ e chanfro meio V, conforme pode ser visto na Figura 1.

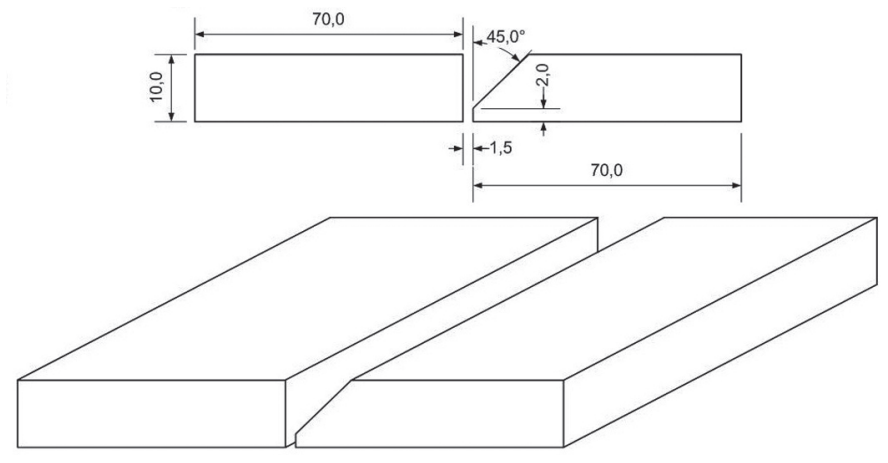

Figura 1. Geometria da junta a ser soldada.

As soldagens das juntas tipo semi-V foram realizadas utilizando corrente contínua, eletrodo positivo (CCEP) e argônio como gás de proteção. Como material de adição, foram empregados arames com diâmetro de 1,2 $\mathrm{mm}$ de Inconel 625 (Tabela 2), uma vez que esta liga apresenta elevado teor de molibdênio, o que diminui uma possível perda deste elemento pelo metal de base na realização da soldagem. A deposição dos cordões de solda foi feita utilizando uma velocidade de alimentação (Valim) de $7,5 \mathrm{~m} / \mathrm{min}$, tensão (U) de $30 \mathrm{~V}$, vazão de gás argônio (Vg) de 20 1/min e distância bico de contato peça (DBCP) de $20 \mathrm{~mm}$. A quantidade de cordões depositados em cada junta soldada variou dependendo dos parâmetros empregados.

Na Tabela 3 são apresentados os valores dos parâmetros de velocidade de soldagem (V), corrente (I), energia (Es) empregados nas soldagens pelo processo MIG na deposição dos cordões de raiz e de enchimento da junta. Após o enchimento da junta o corpo de prova soldado foi virado, sendo realizada a deposição do cordão de solda no lado oposto a raiz da junta, conforme parâmetros apresentados na Tabela 4. 
Tabela 2. Composição química do eletrodo segundo fabricante (\% em massa).

\begin{tabular}{c|c|c|c|c|c|c|c|c|c|c|c}
\hline Eletrodo & $\mathrm{C}$ & $\mathrm{Si}$ & $\mathrm{Mn}$ & $\mathrm{P}_{\text {máx }}$ & $\mathrm{S}_{\text {máx }}$ & $\mathrm{Cr}$ & $\mathrm{Ni}$ & $\mathrm{Mo}$ & $\mathrm{Nb}$ & $\mathrm{Ti}$ & $\mathrm{Fe}$ \\
\hline AWS ERNiCrMo-3 (Inconel 625) & $<0,03$ & 0,2 & 0,2 & 0,015 & 0,015 & 22,0 & $>60,0$ & 9,0 & 3,5 & $<0,20$ & $<1,0$ \\
\hline
\end{tabular}

Tabela 3. Relação entre os níveis de corrente e velocidade de soldagem em uma mesma energia para os cordões de enchimento da junta.

\begin{tabular}{|c|c|c|c|c|}
\hline Condição & $\mathrm{V}(\mathrm{cm} / \mathrm{min})$ & $\mathrm{I}(\mathrm{A})$ & Es $(\mathrm{kJ} / \mathrm{cm})$ & Técnica de Energia (TE) \\
\hline M1 & 38 & \multirow{3}{*}{210} & 10 & $\mathrm{~V}$ \\
\hline M2 & 25 & & 15 & $\mathrm{~V}$ \\
\hline M3 & 19 & & 20 & $\mathrm{~V}$ \\
\hline M4 & \multirow{3}{*}{25} & 140 & 10 & I \\
\hline M2 & & 210 & 15 & I \\
\hline M5 & & 280 & 20 & I \\
\hline
\end{tabular}

Tabela 4. Parâmetros de soldagem empregados no cordão de solda depositado na raiz da junta.

\begin{tabular}{c|c|c|c}
\hline Condição & $\mathrm{V}(\mathrm{cm} / \mathrm{min})$ & $\mathrm{I}(\mathrm{A})$ & $\mathrm{E}(\mathrm{kJ} / \mathrm{cm})$ \\
\hline $\mathrm{R}$ & 60 & 210 & 6 \\
\hline
\end{tabular}

A amostra soldada foi submetida à caracterização das regiões da solda e do metal de base através de exames metalográficos, por microscopia ótica, microscopia eletrônica de varredura (MEV) e por EBSD, para verificar o efeito da energia de soldagem na microestrutura das mesmas. Foram ainda realizados ensaios de dureza Vickers visando levantar um perfil de microdureza das ligas estudadas.

\section{Resultados e Discussão}

\subsection{Estudo Termodinâmico do Sistema Fe-Cr-Mo}

$\mathrm{Na}$ Figura 2a tem-se o diagrama de equilíbrio do sistema Fe$\mathrm{Cr}$, sem a adição de molibdênio, onde se observam a presença do campo austenítico, a possibilidade da formação da fase sigma $(\sigma)$ e, ainda, a estrutura ferrítica característica destes materiais. De acordo com Chiaverini [12] a solubilidade do cromo no ferro gama ( $\mathrm{Fe}-\gamma)$, estrutura cúbica de face centrada (CFC), é de $12,8 \%$, mostrando que o valor obtido no diagrama da Figura 2a, de $13,5 \%$, está coerente.

A fim de melhor caracterizar as possíveis fases presentes na liga E1, foi levantado o diagrama de fases com base na composição química mostrada na Tabela 1 . Como está mostrado na Figura $2 b$, é possível verificar a presença de carbonetos do tipo $\mathrm{M}_{23} \mathrm{C}_{6}$ e $\mathrm{M}_{6} \mathrm{C}$, e das fases chi $(\chi)$, mu $(\mu)$ e sigma $(\sigma)$, além da fase ferrítica e austenítica.

A formação de fases intermetálicas, chi $(\sigma), \mathrm{mu}(\mu)$ e sigma $(\sigma)$, fragilizam os aços, devendo ser na medida do possível evitada. Tratamentos termomecânicos podem ser realizados para atingir-se uma condição de meta-estabilidade, visto que resfriamentos bruscos podem tornar a difusividade tão baixa que o estado de equilíbrio nunca, ou quase nunca seja atingido. Este comportamento pode ser conseguido através de um tratamento térmico de solubilização.

Para obtenção da temperatura de solubilização, considerou-se somente a temperatura acima da qual só existisse a fase ferrítica, correspondendo a $880{ }^{\circ} \mathrm{C}$. Optou-se por realizar o tratamento com um acréscimo de $50{ }^{\circ} \mathrm{C}$ na temperatura obtida objetivando evitar a possível formação dessas fases indesejáveis.

\subsection{Caracterização Microestrutural da Liga Solubilizada}

Na Figura 3 é apresentada a microscopia ótica da seção transversal da liga após a realização da solubilização.

Como pode ser verificado na Figura 3, têm-se uma microestrutura característica desta liga, do tipo ferrítica e, ainda, a presença de alguns pequenos precipitados, provavelmente formados devido à presença de carbono presentes nestas ligas.

A microestrutura obtida após as solubilizações confirma os resultados do diagrama levantado com o uso do programa termodinâmico, indicando que de acordo com a composição, a liga estudada deveria apresentar uma estrutura cúbica de corpo centrado (CCC) e ainda a possibilidade de fases precipitadas. Dentre as fases precipitadas que poderiam ter sido formadas têm-se as fases sigma $(\sigma)$, chi $(\chi)$ e mu $(\mu)$, contudo, como foi observado na Figura 3, após a solubilização nenhum indício da formação destas fases foi verificado. A análise feita através da técnica de ESBD mostrou que $99,8 \%$ da superfície analisada correspondem à ferrita. 


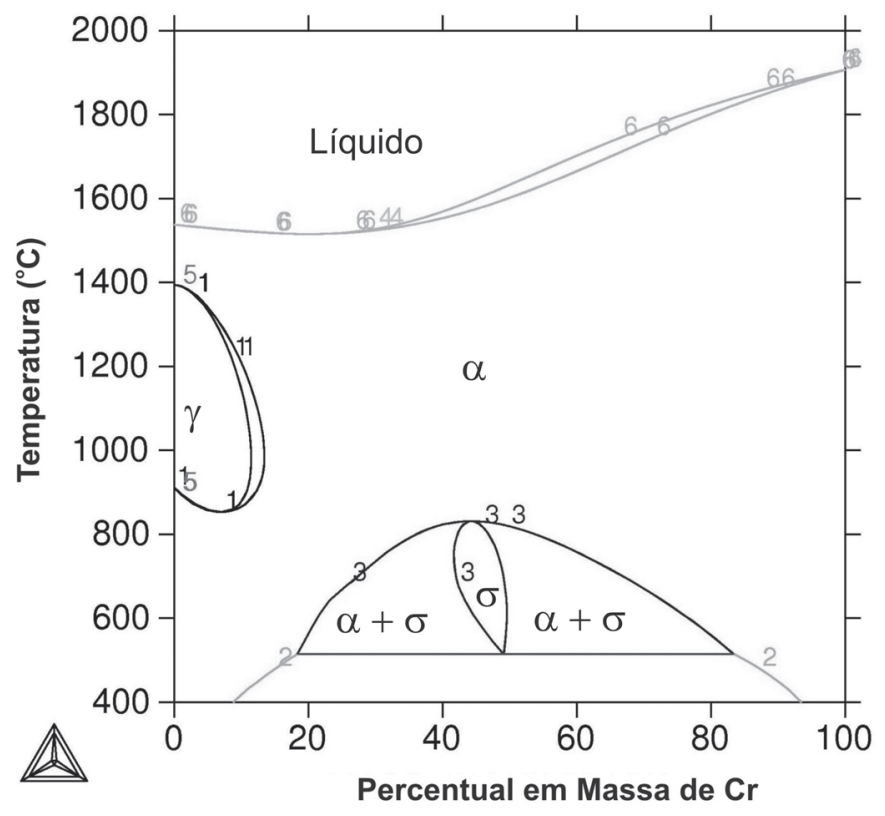

(a)

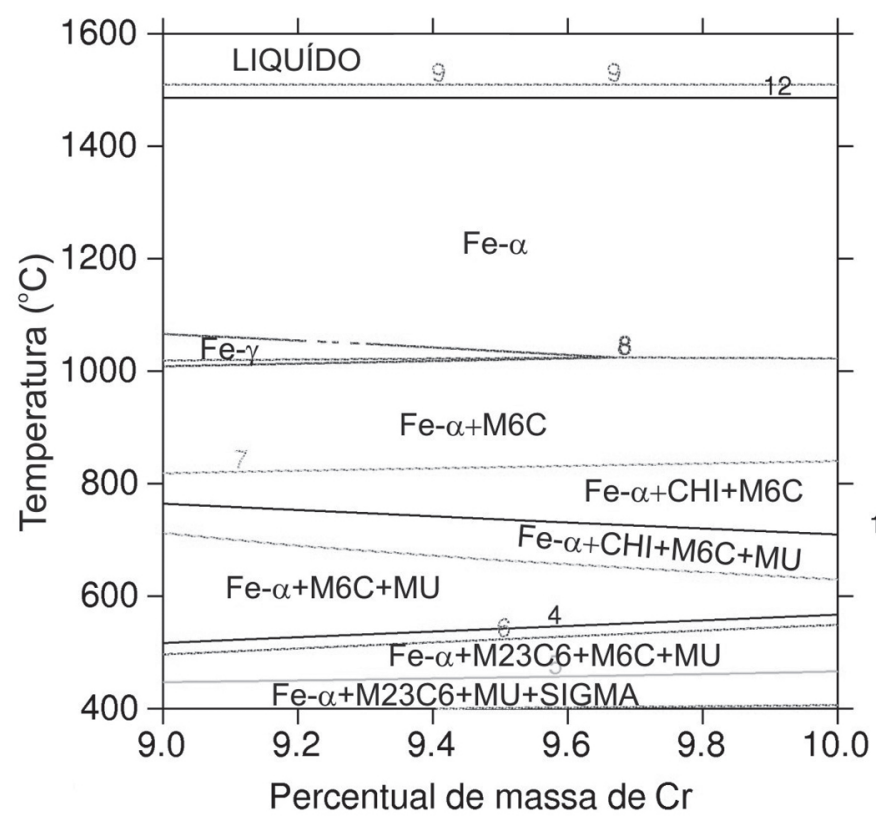

(b)

Figura 2. a) Diagrama Fe-Cr. b) Diagrama da liga E1 (9,5\% Cr - 5,3\% Mo).

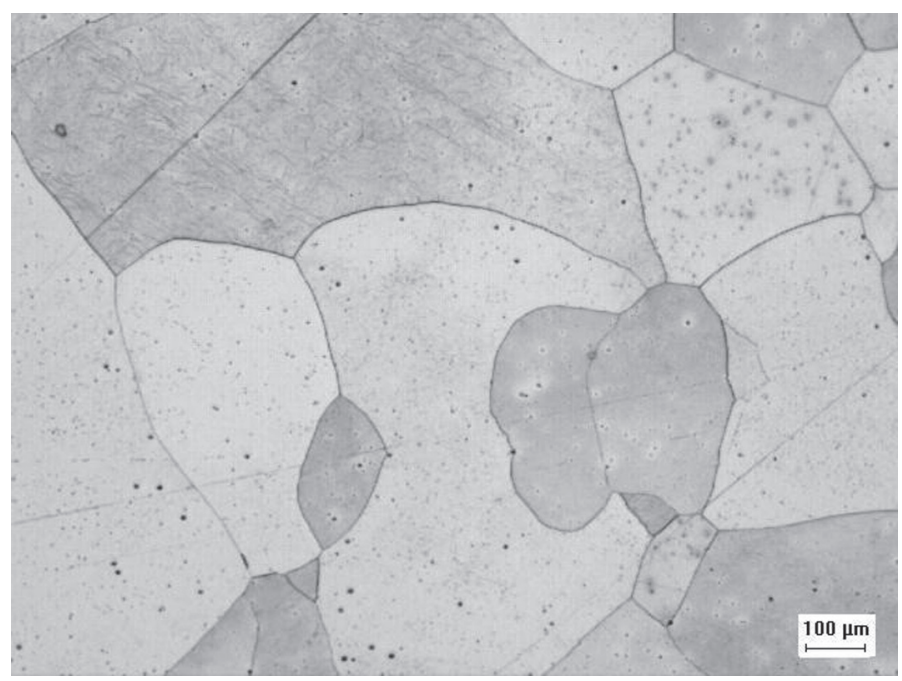

Figura 3. Liga solubilizada. Aumento: $100 \mathrm{X}$

A medição do tamanho de grão da liga, feita através de um programa empregado na EBSD e do método ASTM, resultou num valor médio de 1,0 ASTM, sendo considerado um tamanho de grão grande. Ressalta-se que o aumento no tamanho de grão é um dos fatores responsáveis pelo aumento da temperatura de transição dúctil frágil de ligas ferríticas, podendo assim prejudicar a tenacidade dessas ligas $[13,14]$. Por outro lado, a soldagem de materiais de grão grande pode favorecer a ocorrência de trincas, prejudicando a soldabilidade desses materiais.

O problema do crescimento de grão pode ser minimizado pela aplicação de baixas energias de soldagem que reduzem a velocidade de crescimento e a extensão dos grãos [15].

O levantamento da dureza desta liga resultou em um valor médio de 196 HV. Verifica-se que este valor de dureza é superior ao de ligas comerciais como o aço ASTM A-213 T9 (dureza de
178 HV) com composição de 8,0\% - 10\% de Cr, Mo entre $0,9 \%$ e $1,1 \%$ e $0,15 \%$ máximo de $\mathrm{C}$ [15]. O maior valor de dureza para liga com maior percentual de molibdênio vem a confirmar o efeito endurecedor deste elemento. Por outro lado, observa-se que este aumento na dureza não foi significativo, uma vez que corresponde a uma diferença de $18 \mathrm{HV}$.

\subsection{Soldagem com Adição de Material}

A macrografia da Liga E1, após a soldagem, está mostrada na Figura 4. Um dos possíveis problemas na soldagem de ligas ferríticas é a formação de defeitos ao longo da zona afetada pelo calor (ZAC), como ocorrência de trincas. Contudo, como pode ser verificado, a macrografia indica que foi possível realizar a soldagem dissimilar, com a adição de material, proporcionando a união dos corpos de prova de acordo com o desenho apresentado na Figura 1 sem a presença de defeitos, independente do parâmetro empregado.

O círculo na figura indica a presença de falta de fusão associados ao posicionamento da tocha em relação à peça a

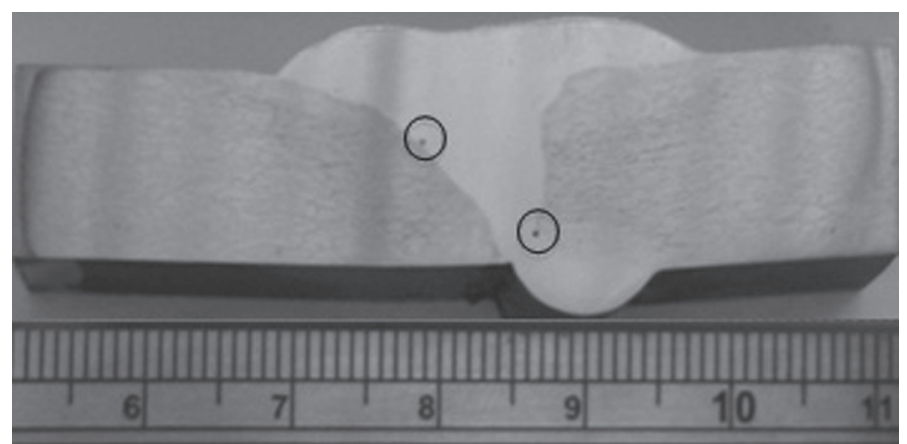

Figura 4. Macrografia após soldagem com adição de material da liga E1 parâmetro M2. 


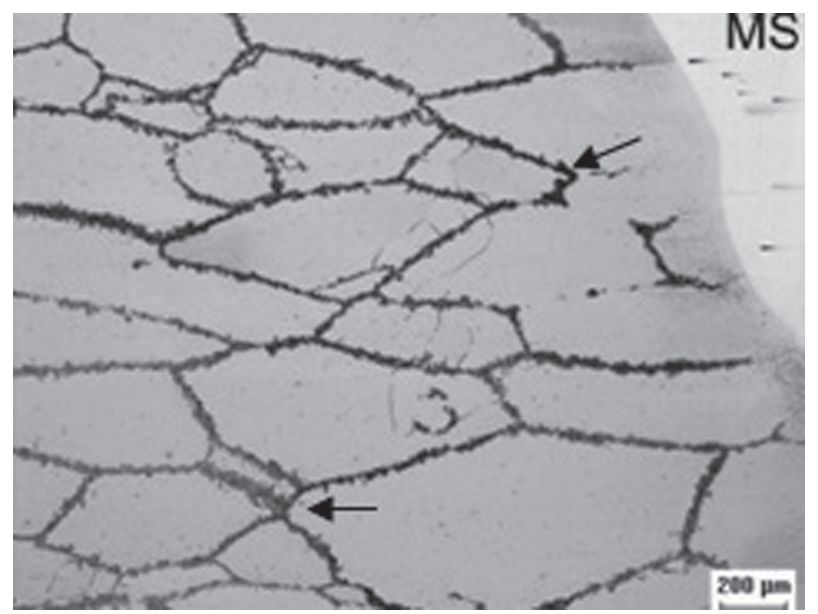

(a)

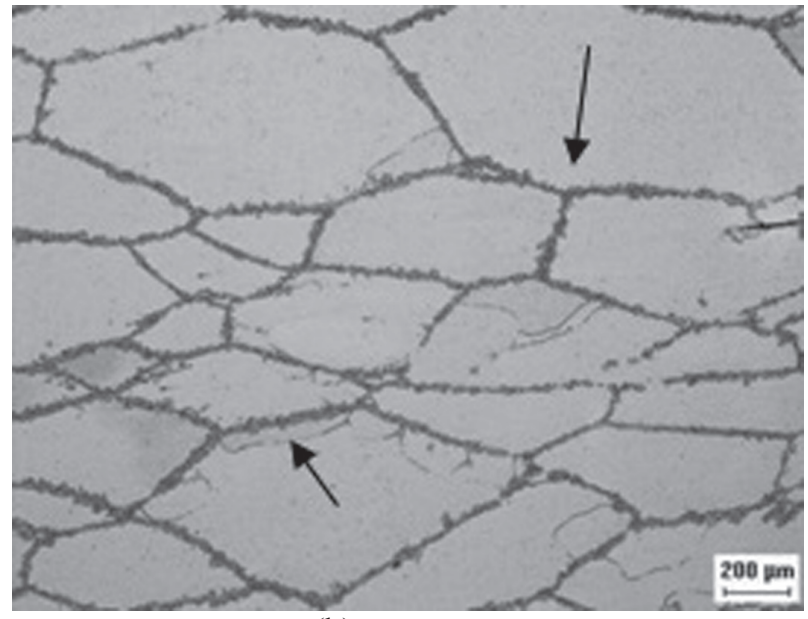

(b)

Figura 5. Micrografia da solda com adição de material da liga E1, parâmetro M1. Aumento 50 X. Ataque: Vilella. a) MS-ZAC. b) ZAC-MB.

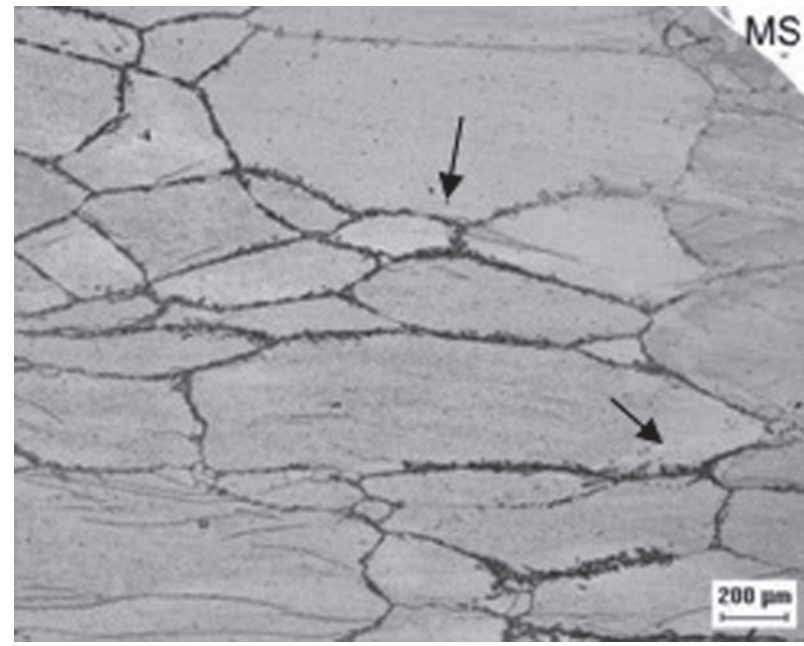

(a)

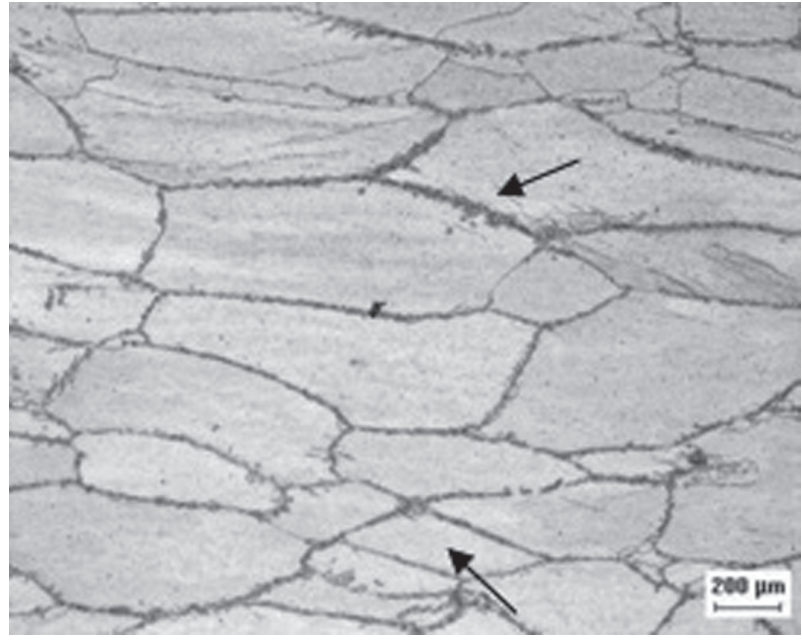

(b)

Figura 6. Micrografia da solda com adição de material da liga E1, parâmetro M4. Aumento 50 X. Ataque: Vilella. a) MS-ZAC. b) ZAC-MB.

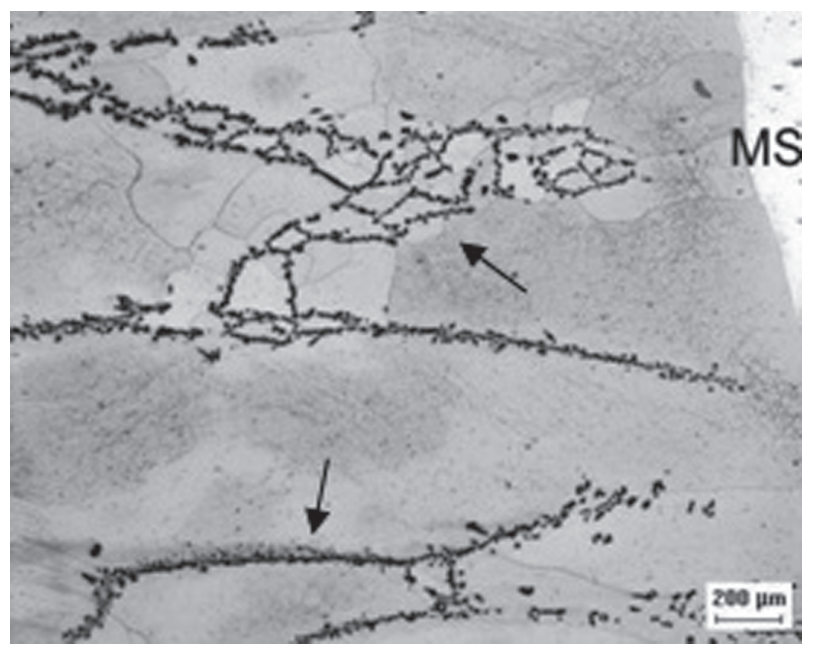

(a)

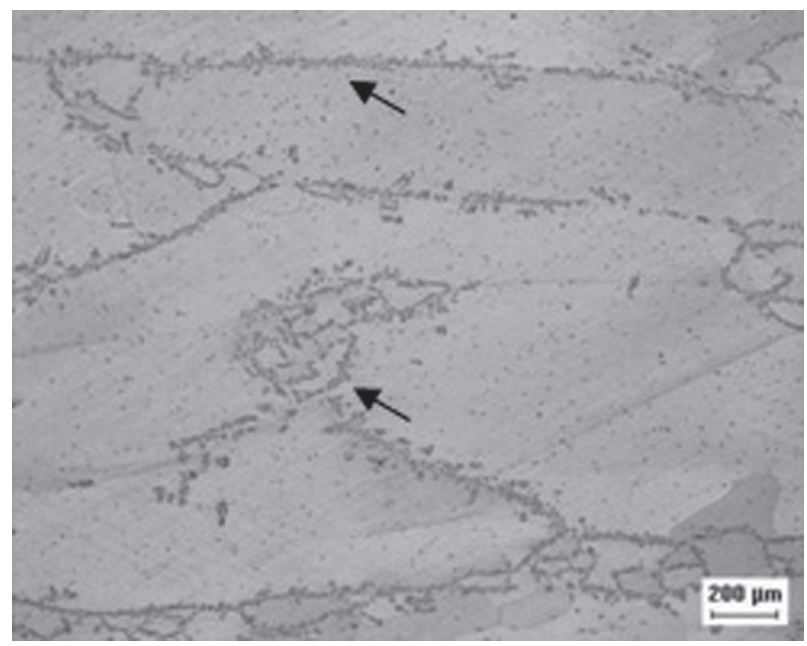

(b)

Figura 7. Micrografia da solda com adição de material da liga E1, parâmetro M5. Aumento 50 X. Ataque: Vilella. a) MS-ZAC. b) ZAC-MB. 
ser soldada e não a possíveis problemas entre as peças a serem unidas e o material de adição. O comportamento observado nas macrografias foi verificado em todas as soldagens realizadas, independente da energia de soldagem e da técnica de energia.

A ZAC e o metal de base (MB) da liga E1 são apresentados da Figura 5 a Figura 7 onde é possível perceber, além da microestrutura ferrítica característica desta liga, a presença de regiões escuras ao longo de todo o contorno de alguns grãos (indicadas pelas setas nas figuras).

De acordo com o diagrama da Figura 2b, a liga E1 pode apresentar além da fase ferrítica, a formação da fase austenítica e das fases intermetálicas chi $(\chi)$, mu $(\mu)$ e sigma $(\sigma)$. Uma vez que estas fases são difusionais, as mesmas necessitariam de um certo tempo para se formarem. As soldagens foram realizadas sem controle de pré-aquecimento favorecendo um resfriamento rápido, minimizando a possibilidade de formação destas fases. Por outro lado, a presença da fase austenítica (Figura $2 b$ ) aliada às condições de soldagem observadas, indicam que uma possível fase que poderia aparecer seria a martensita (não difusional).

Independente da técnica de energia, Tipo I ou V, não foi verificado nenhuma variação na microestrutura da liga E1 após as soldagens realizadas.

Silva [16] verificou a formação de martensita, com morfologia semelhante à apresentada nas Figura 5 a Figura 7, no aço ferrítico AISI $410 \mathrm{~S}$ submetido à soldagem com eletrodo revestido empregando diferentes níveis de energia [16], conforme verificado na Figura 8.

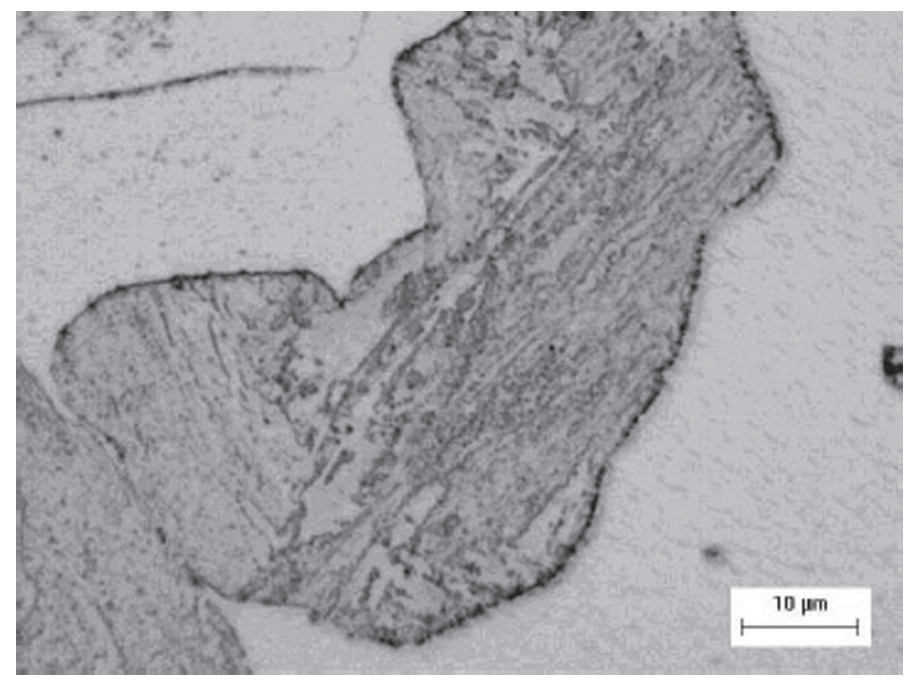

Figura 8. Precipitado na interface ferrita/martensita [16]. Aumento de 1000X.

A partir disto foram realizadas as análises por EBSD na amostra soldada da Liga E1, conforme está mostrado na Figura 9 e Tabela 5, onde é possível verificar que, além do Fe- $\alpha$, há a presença da fase martensita nos precipitados observados na solda da liga E1.

A formação de uma rede de martensita ao longo dos contornos de grão de aços ferríticos (no caso de ligas com maiores teores de intersticiais) é uma das causas da fragilização da região da solda [5].

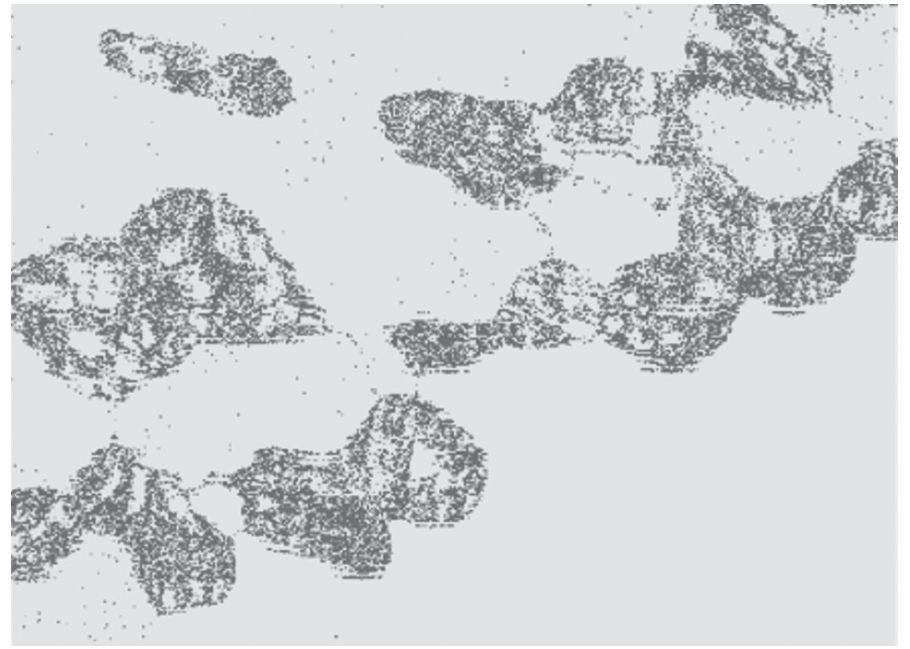

Figura 9. EBSD da liga E1, aumento de 4000X.

Tabela 5. Percentual das fases identificadas através do EBSD da Figura 9.

\begin{tabular}{c|c}
\hline Fase & $\%$ \\
\hline Não Identificada & 3,2 \\
\hline Ferro alfa (área clara) & 78,6 \\
\hline Martensita (área escura) & 18,2 \\
\hline
\end{tabular}

$\mathrm{Na}$ tentativa de evidenciar a presença da martensita, a liga E1 soldada foi submetida a um reagente chamado de Rigsbee and Vander Arend [11], específico para revelação desta fase. O aspecto da martensita está mostrado na Figura 10. Este resultado é mais uma evidência da formação de martensita após a solda da liga E1.

Foram realizadas análises por MEV e EDX tanto nos precipitados quanto na matriz da liga E1 (Figura 11 e Figura 12). Como pode ser visto na Figura 11 observa-se uma microestrutura típica da martensita em placas. O EDX apresentado na Figura 12 mostra que não há diferença na composição química entre o precipitado observado e a matriz do material, fortalecendo a hipótese da martensita.

Na Figura 13 está mostrado o perfil de microdureza Vickers para a liga soldada com adição de material. Verifica-se que o perfil de microdureza não apresentou mudança significativa entre os diferentes parâmetros empregados

Ao analisar a influência da técnica de energia na microdureza das ligas (Figura 14 e Figura 15), comparando as duas técnicas, observa-se que nem técnica do tipo V, tampouco a técnica do tipo I promoveram alterações no comportamento da microdureza ao longo das regiões analisadas. Observa-se ainda que para todos os parâmetros, independente da técnica de energia, a existência de alguns picos de dureza, os quais estão associados à presença de martensita, o que pode explicar os maiores valores de dureza da Liga E1 após a soldagem quando comparado a mesma liga solubilizada (196 HV). Contudo, a dureza da martensita formada nesta liga é ainda inferior aos valores encontrados em outras ligas conhecidas, cujos valores podem atingir $700 \mathrm{HV}$. 


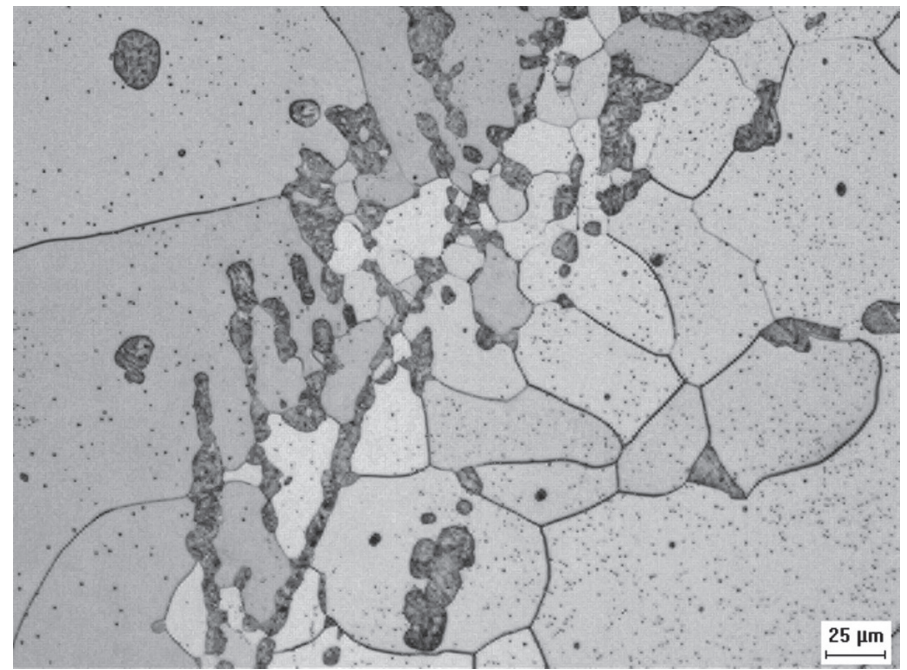

(a)

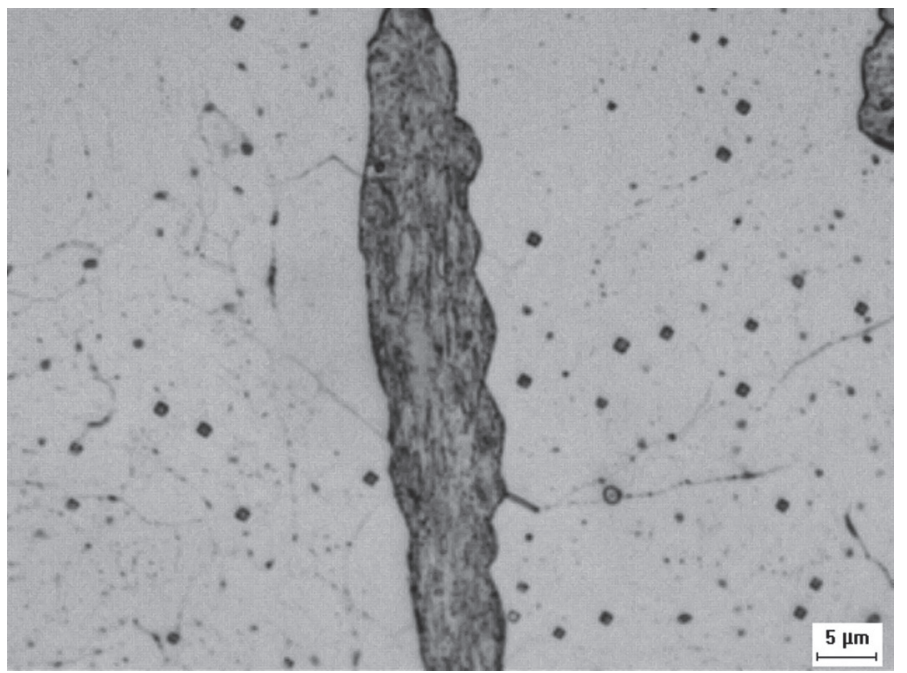

(b)

Figura 10. Microscopia ótica da martensita na liga E1. a) Aumento 200X. b) Aumento 1000X.

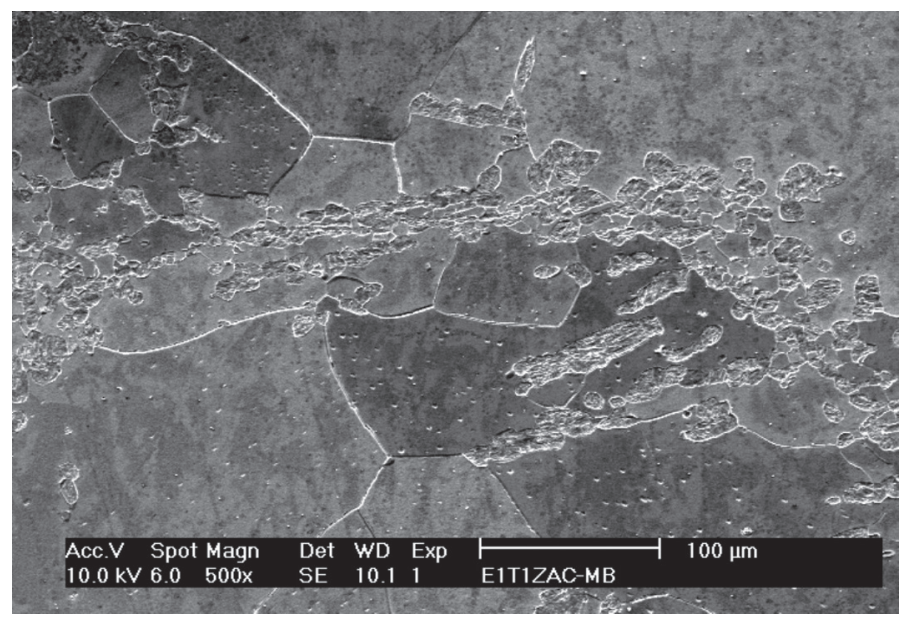

(a)

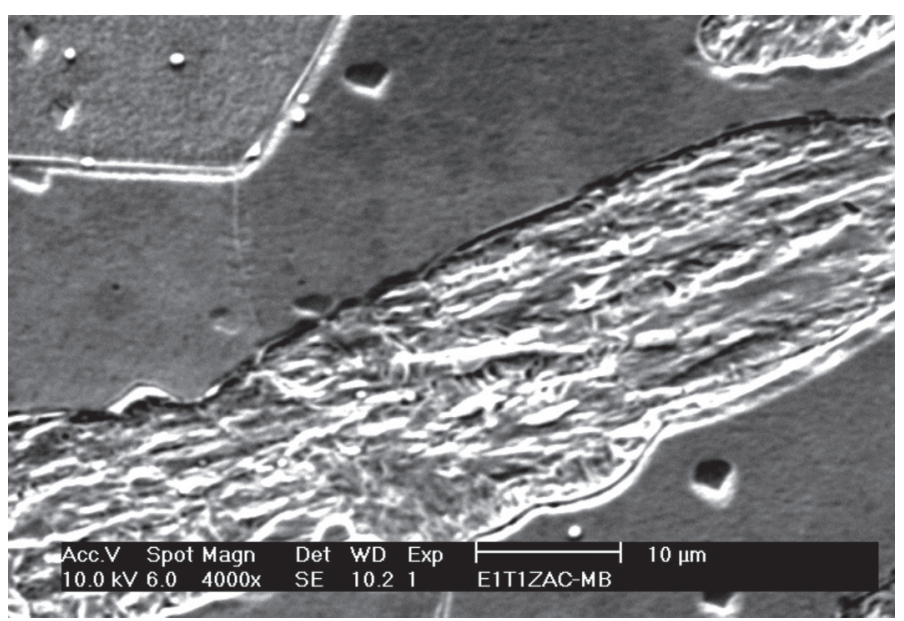

(b)

Figura 11. Microestrutura dos precipitados observados nas regiões após a solda da Liga E1. a) Aumento de 500X. b) Aumento de 4000X.
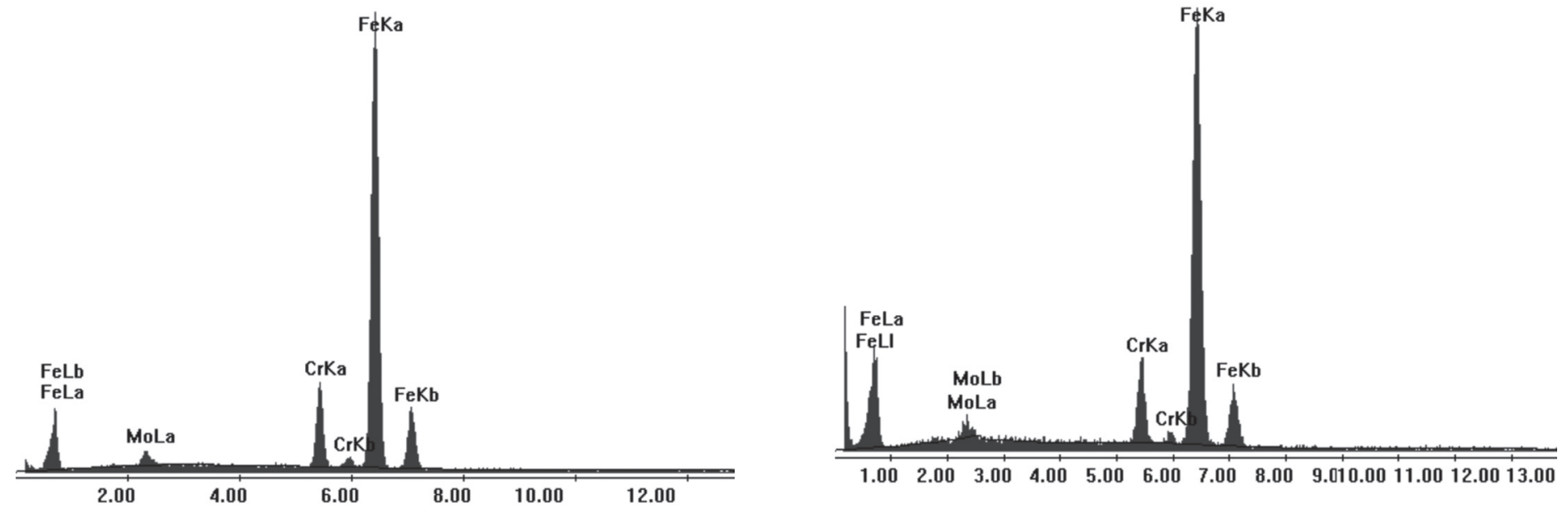

Figura 12. Análise de composição química das regiões após o metal de solda da liga E1. a) Precipitado (Figura 12b). b) Matriz da liga E1. 


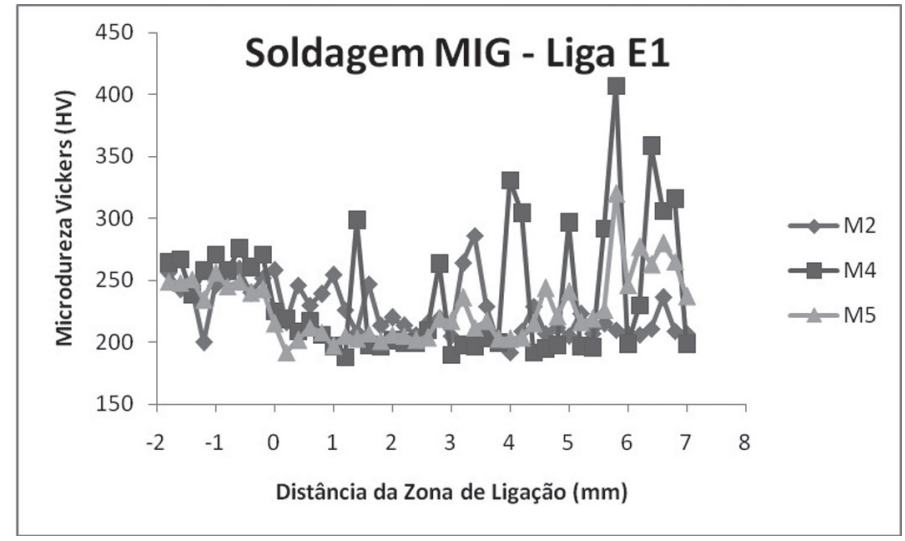

Figura 13. Efeito dos parâmetros de soldagem no perfil de microdureza da liga E1 soldada com adição de material.

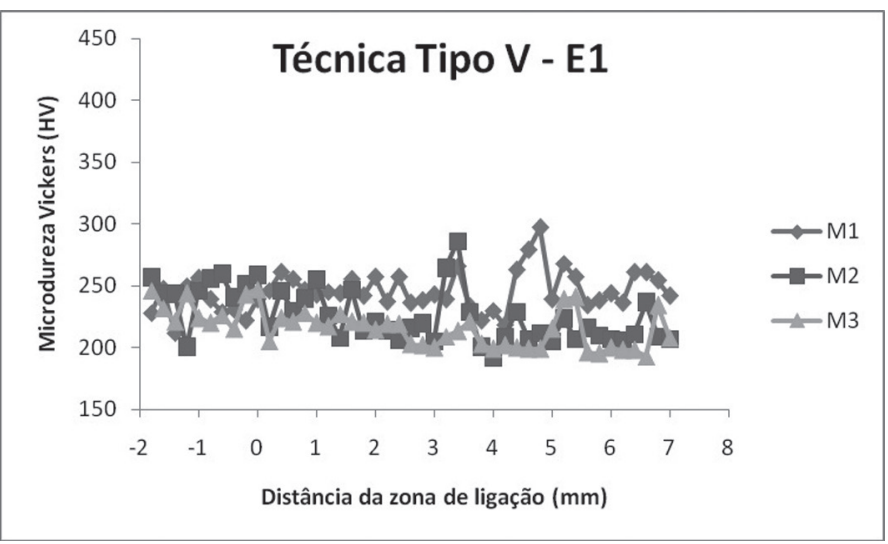

Figura 14. Efeito da técnica de energia do tipo V no perfil de microdureza da liga E1 após soldagem com adição de material.

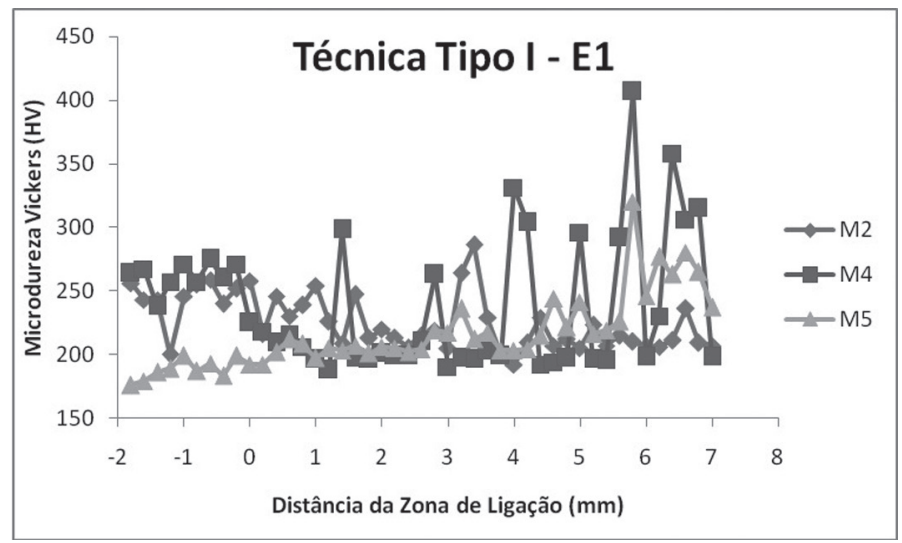

Figura 15. Efeito da técnica de energia do tipo I no perfil de microdureza da liga E1 após soldagem com adição de material.

\section{Conclusões}

- A liga E1 apresentou uma estreita faixa de temperatura de austenitização, podendo favorecer a uma transformação martensítica.

- Apesar do alto teor de molibdênio favorecer a formação de fases precipitadas que são prejudiciais as propriedades desta liga, a adequada análise dos resultados dos estudos termodinâmicos permitiu a correta seleção das condições para a realização dos tratamentos de solubilização de forma que fosse possível obter uma microestrutura ferrítica.

- A dureza da liga estudada foi superior a de ligas comerciais semelhantes, com microestrutura ferrítica, como, por exemplo, o aço 9Cr-1Mo.

- A liga E1 apresentou ao longo da ZAC da solda, a presença de alguns precipitados, com altos valores de dureza, identificados como sendo martensita, formados nos contornos de grão.

- A dureza da martensita observada na liga E1 não foi superior a $400 \mathrm{HV}$, possivelmente associada ao baixo teor de carbono presente, indicando que esta fase pode não prejudicar as propriedades mecânicas da liga.

- A análise da técnica de energia de soldagem mostrou que não houve mudanças na microestrutura nem na dureza da liga.

- Com exceção aos precipitados observados, nenhum outro defeito, como a presença de trincas, foi observado nos corpos de prova soldado para os diferentes parâmetros empregados.

\section{Agradecimentos}

Os autores gostariam de agradecer ao Laboratório de Caracterização de Materiais e ao Laboratório de Engenharia de Soldagem da Universidade Federal do Ceará pela realização dos experimentos, além do CNPq, FUNCAP e CAPES e PETROBRÁS pelo suporte financeiro.

\section{Referências Bibliográficas}

[1] PÉREZ, G. J. A. Caracterização das Fases Presentes em Depósitoo de Níquel ER-NiCrMo-3 em Tubos de Aço de 9Cr 1Mo Usados em Fornos de Refinária de Petróleo: 2005, 129p. Dissertação (Mestrado) - Faculdade de Engenharia Metalúrgica e de Materiais, Universidade Federal do Ceará, Fortaleza.

[2] CUNHA, B. R. M. da. Soldabilidade Da Nova Geração De Aços Ferríticos Cr-W Resistentes A Altas Temperaturas. UFRJ COPPE, Rio de Janeiro - RJ, 2006.

[3] SOUZA, S. A., Composição Química dos Aços. São Paulo, Edgard Blücher, 1989

[4] WU, X. Q.; et al. Resistance of Mo-bearing stainless-steel coating to naphthenic acid corrosion and erosion-corrosion. Corrosion Science 46, p1013-1032, 2004.

[5] MARQUES, P. V.; MODENESI, P. J.; BRACARENSE, A. Q. Soldagem: Fundamentos e Tecnologia. Ed. UFMG, Belo Horizonte, 2005, 363p.

[7] PICKERING, F.B. Physical metallurgy of stainless steel developments. International Metals Reviews, Review 211, p.227-249, Dec., 1976.

[8] OHASHI, N.; ONOJ Y. KINOSHITA, N.; YOSHIOKA, $\mathrm{K}$; Effects of metallurgical and mechanical factors on Charpy impact toughness of extra low interstitial ferritic stainless steels. In: SYMPOSIUM ON FERRITIC STAINLESS STEELS, San Francisco, 1979. Philadelphia, ASTM, 1980, p.202-220.

[9] FOLKHARD, E., Welding Metallurgy of Stainless Steels. Springer, Vienna, 1988. 
[10] EDSTRÖM, H. J., LJUNDBERG, L., Rost- und säurebeständige Chrom-Nickel- Stähle mit max. 0,030\% Kohlenstoff als Kontruktionsmaterial für die chemische Industrie. Werkst. u. Korrosion 15, 743-753, 1964.

[11] VOORT G.F.V., et al.(Eds,). ASM Handbook: Metallography and Microstructures. Vol. 9, USA: ASM International, p. 284, 1992.

[12] CHIAVERINI, V. Aços e ferros fundidos. 6 ed., São Paulo, Associação Brasileira de Metais, 1988.

[13] KAH, D. H., DICKINSON, D. W., Weldability of the Ferritic Stainless Steels. Welding Journal, p.135s-142s, Ago. 1981.

[14] BRANDI, S. D. Estudo da soldabilidade do aço inoxidável duplex DIN W: 1992. Tese (Doutorado) - Escola Politécnica, Universidade de São Paulo, São Paulo.

[15] MUNGOLE, M.N., et al. Recrystalised grain morphology in $9 \mathrm{Cr} 1 \mathrm{Mo}$ ferritic steel. Materials Science Engineering A 476, p.140-145, 2008.

[16] SILVA, C. C., et al. Alterações Microestruturais na ZAC do aço inoxidável ferrítico $410 \mathrm{~S}$ - Efeitos sobre a resistência à corrosão. Soldagem \& Inspeção 11, 2006. 